\title{
In Situ Methods for Metal-Flux Synthesis in Inert Environments
}

Ashley Weiland, ${ }^{1}$ Matthew G. Frith, ${ }^{2}$ Saul H. Lapidus, ${ }^{2 *}$ Julia Y. Chan ${ }^{1 *}$

${ }^{1}$ Department of Chemistry \& Biochemistry, University of Texas at Dallas, Richardson, Texas

75080, USA

${ }^{2}$ X-ray Science Division, Advanced Photon Source, Argonne National Laboratory, 9700 S. Cass

Ave, Argonne, Illinois 60439, USA

*Corresponding author's email address: slapidus@anl.gov and Julia.Chan@utdallas.edu

\section{Preliminary Designs}

Figure S1a shows the first in situ synthesis attempt using a horizontal set up where the sample was heated with a hot air blower. Unfortunately, with a horizontal orientation when the sample melted, the liquid reactants can move out of the beam. Therefore, the set up was adjusted to hang the sample vertically, as shown in Figure S1b. However, the hot air blower can only heat a small area with a maximum temperature of $999^{\circ} \mathrm{C}$, where the thermocouple is measuring the temperature of the air coming out of the blower, and not necessarily the temperature of the area around the sample. 

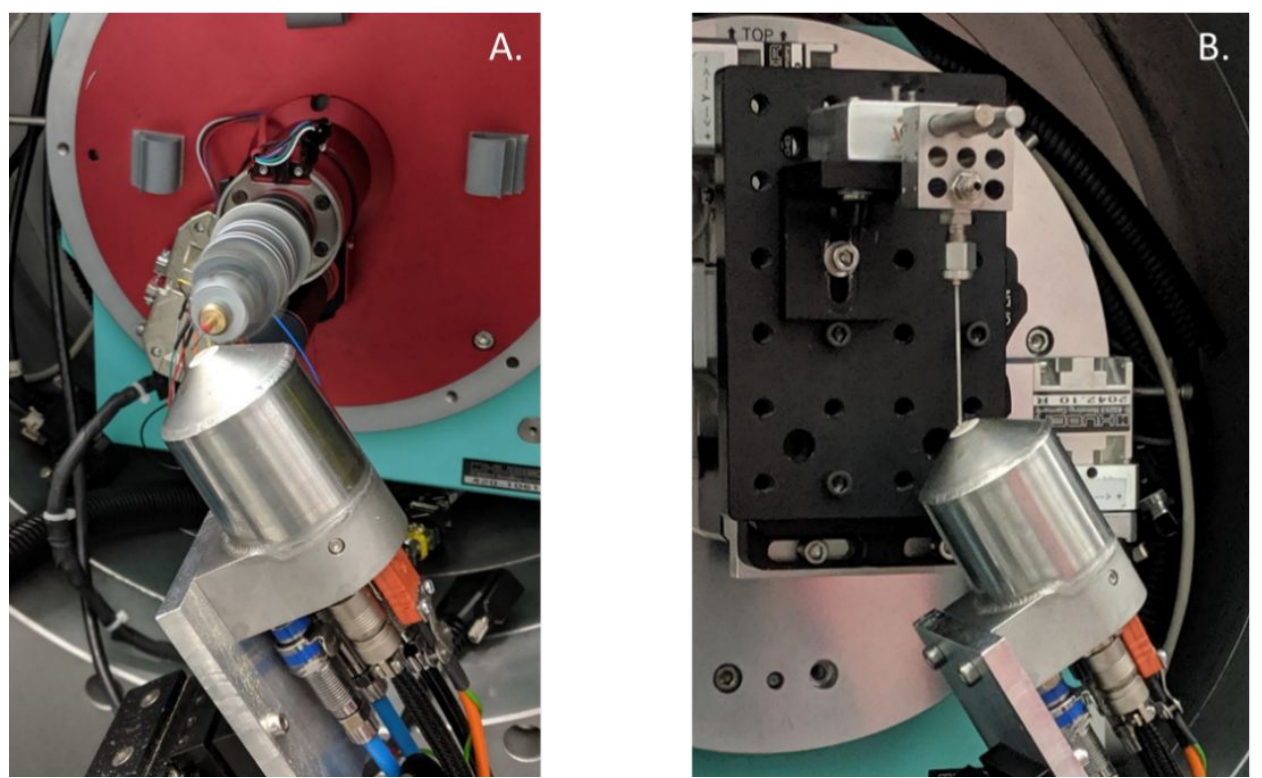

Figure S1. In situ synthesis attempt with the hot air blower as the heating method. (a) Horizontal configuration that was deemed problematic. (b) Vertical configuration designed to keep the liquidous sample from flowing out of the beam.

Figure S2 shows the next model, which utilized a vertical sample orientation to allow for the evaluation of metal flux synthetic methods where the flux becomes liquidous during the reaction profile, and a modified resistive furnace based on the flow cell design ${ }^{1}$ where two Kanthal A-1 resistive wires are wrapped around ceramic rods with the sample placed between them. These furnaces are well known to go up to a maximum of $1050{ }^{\circ} \mathrm{C}$ but not for as long as required (48 hours) and not the required $1100{ }^{\circ} \mathrm{C}$, which is in part due to heat loss in all directions. To extend the working range of the resistive coils, the sample was placed in the center of the coil for homogenous heat treatment. The coils were wrapped in insulation to reduce heat loss. A small section of insulation was removed from both sides, using tweezers, to allow for the beam to pass through. A thermocouple was placed near the bottom of the sample, closest to where the beam would go through. Practice trials reached the desired temperature of $1100{ }^{\circ} \mathrm{C}$ and lasted there for over three days. 

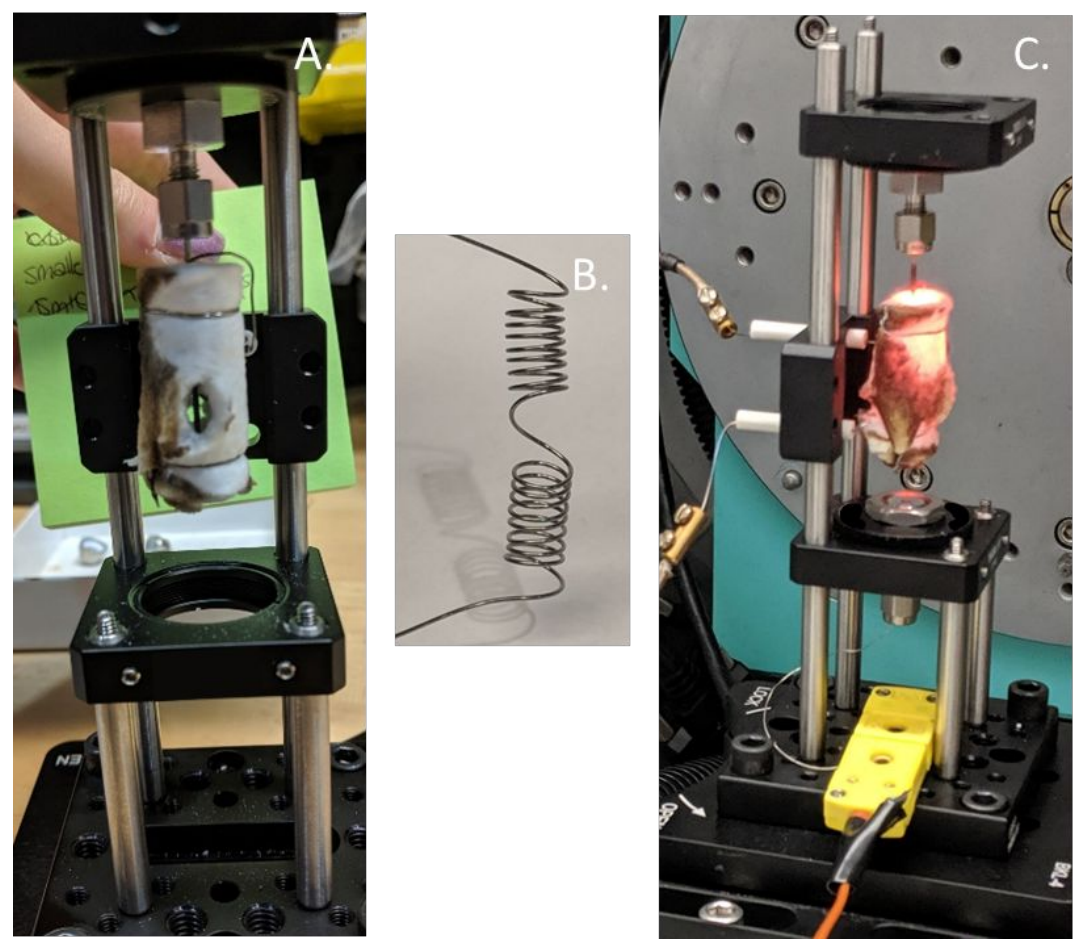

Figure S2. A vertical sample orientation with a resistive coil wrapped in insulation as the heat source. (a) A view of the apparatus highlighting the hole in the insulation allowing for the beam to pass through. (b) The coiled Kanthal wire that will be wrapped in insulation to be used as the heat source. (c) The sample environment and furnace in use.

However, the Kanthal wire interfered in the powder patterns (despite pulling the coil apart) and the coil, which was only held in place by the two ceramic rods, was unstable. If wires running current through the coil were moved, the entire coil would move. This was problematic due to the fragile nature of the thin sample capillary. Any small movements from the coil could snap the capillary, exposing the sample to oxygen. Additionally, a motor attachment was desired to prevent preferred orientation in the sample grains. Therefore, a modified design was required to ensure stability and prevent coil from being in the beam.

\section{Design/Assembly}

Table S1. A list of components used in the in situ sample environment.

\begin{tabular}{|c|c|c|c|}
\hline \multicolumn{3}{|l|}{} \\
\hline 1 & Newport BKL-4 & $8 \mathrm{e}$ & $\begin{array}{c}\text { Supeltex M-2A Ferrule } 0.4 \mathrm{~mm} \\
(503258)\end{array}$ \\
\hline
\end{tabular}




\begin{tabular}{|c|c|c|c|}
\hline 2 & $\begin{array}{l}\text { Thorlabs Universal Base Plate } \\
\text { (UBP2) }\end{array}$ & $8 \mathrm{f}$ & $\begin{array}{l}\text { Swagelok Tube Fitting 1/16" nut } \\
\text { (SS-102-1) }\end{array}$ \\
\hline 3 & $1 / 420$ bolts & 9 & $6 \mathrm{~mm}$ o.d. Fused Silica Tube \\
\hline 4 & $\begin{array}{l}\text { Thorlabs Cage Assembly Rods } \\
\text { (ER8) }\end{array}$ & 10 & $\begin{array}{c}\text { Thorlabs Right-Angle Adapter } \\
\text { (SP30) }\end{array}$ \\
\hline 5 & $\begin{array}{l}\text { Thorlabs Cage Assembly Rods } \\
\text { (ER4) }\end{array}$ & 11 & $\begin{array}{l}\text { Omega Mullite Rods (x 4) (DH-1- } \\
\text { 20-100) }\end{array}$ \\
\hline 6 & $\begin{array}{c}\text { Thorlabs Threaded Cage Plate } \\
\text { (CP02) }\end{array}$ & 12 & 2 Wrapped Kanthal Wires (20 GA) \\
\hline 7 & Thermocouple Type K & 13 & $\begin{array}{c}\text { McMaster-Carr Ultra-High- } \\
\text { Temperature Ceramic Fiber } \\
\text { Insulation, Alumina Silica } \\
(93285 \mathrm{~K} 15)\end{array}$ \\
\hline $8 \mathrm{a}$ & $\begin{array}{l}\text { Swagelok Tube Fitting 1/4" nut } \\
\text { (SS-402-1) }\end{array}$ & 14 & $\begin{array}{l}\text { Thorlabs Cage Assembly Rods } \\
\text { (ER4) turned down to reduce } \\
\text { stress }\end{array}$ \\
\hline $8 \mathrm{~b}$ & $\begin{array}{l}\text { Supeltex M-2A Ferrule 1/4 in. } \\
(22481)\end{array}$ & 15 & $\begin{array}{c}\text { Thorlabs Threaded Cage Plate } \\
\text { (CP02) }\end{array}$ \\
\hline $8 \mathrm{c}$ & $\begin{array}{l}\text { Thorlabs Threaded End Cap } \\
\text { (SM1CP2M) - center drilled out }\end{array}$ & 16 & $\begin{array}{c}\text { Modified Swagelok Straight } \\
\text { Fitting (1/16 in. Tube OD x 1/4 in. } \\
\text { Male NPT, part number SS-100-1- } \\
\text { 4) }\end{array}$ \\
\hline $8 \mathrm{~d}$ & $\begin{array}{l}\text { Swagelok Tube Fitting, reducing } \\
\text { Union, } 1 / 4 " \times 1 / 16 \text { " (SS-400-6-1) }\end{array}$ & 17 & $\begin{array}{l}\text { Vextya Stepping Motor (PX243M- } \\
\text { 02BA) }\end{array}$ \\
\hline
\end{tabular}



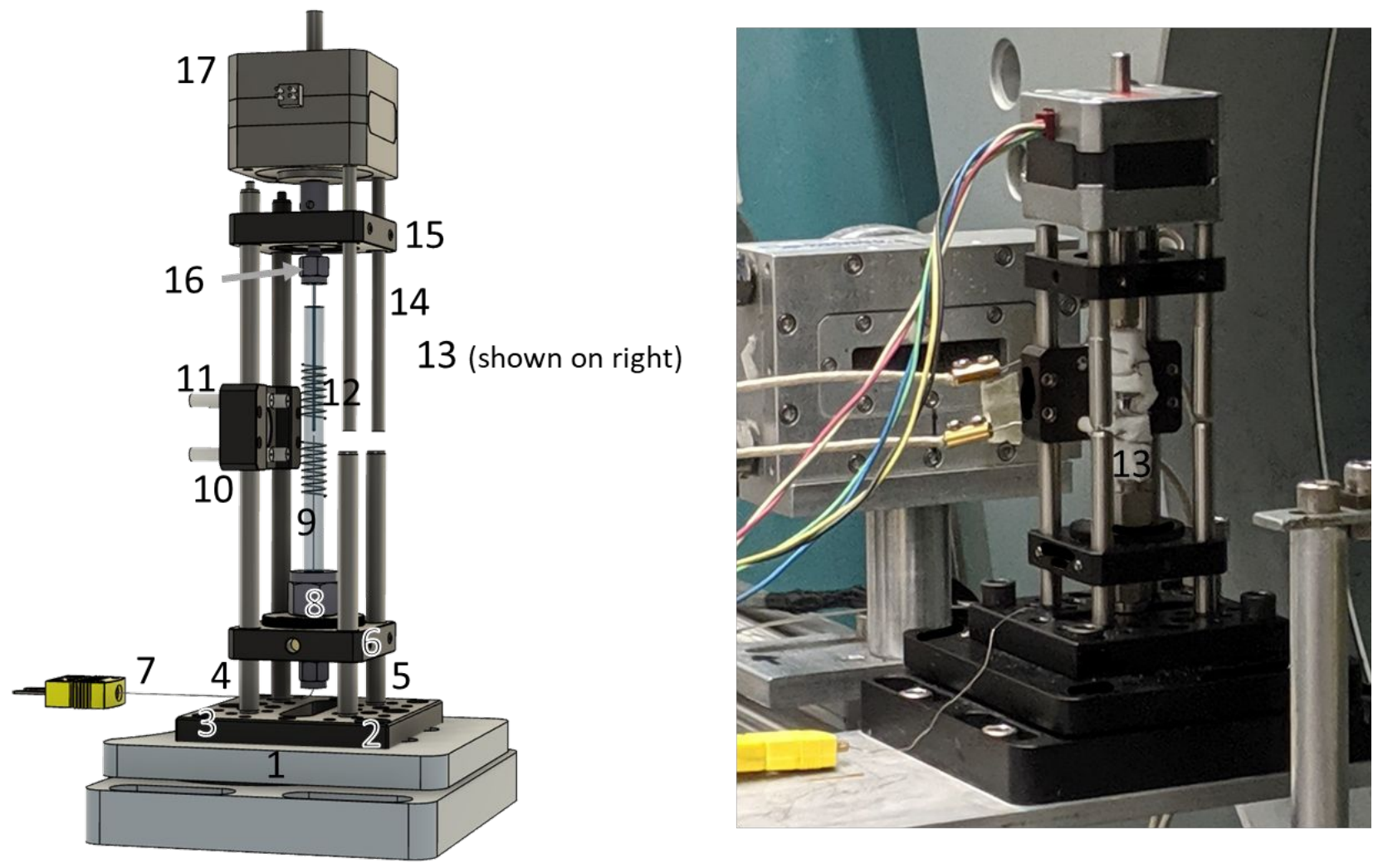

Figure S3. A schematic (left) and image (right) of the furnace apparatus with numbers corresponding to Table $\mathrm{S} 1$ to indicate each part description.

The high-temperature electric resistance furnace, parts listed in Table S1 and corresponding schematic in Figure S3, is heated by two Kanthal wires and can heat air sensitive samples to temperatures up to $1100{ }^{\circ} \mathrm{C}$ for $>40$ hours and hold temperatures below $1000{ }^{\circ} \mathrm{C}$ for $>60$ hours. The vertical sample orientation allows for the evaluation of metal flux synthetic methods where the metal flux becomes liquidous during the reaction profile. 


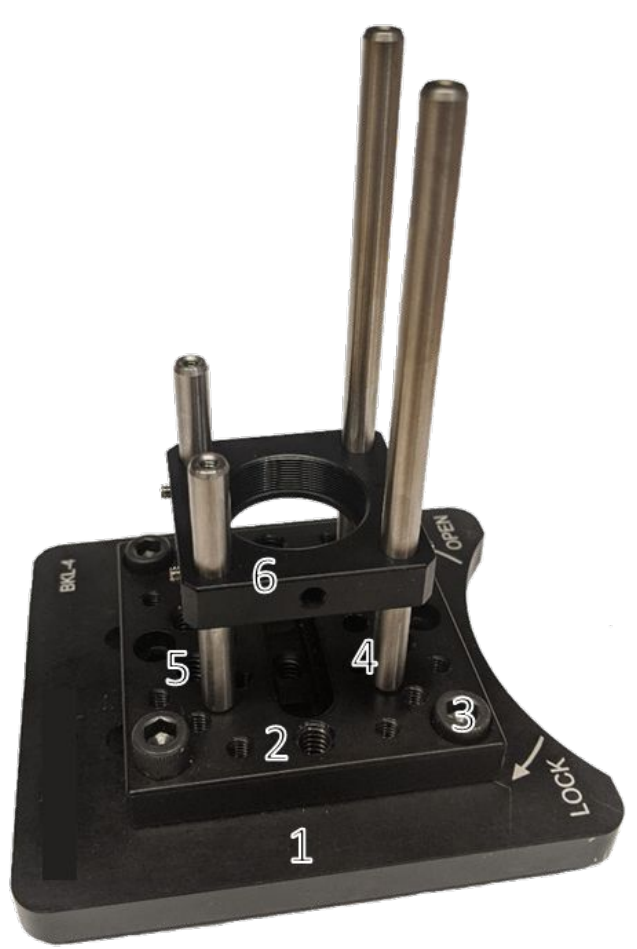

Figure S4. A photo of the base and framework for the sample environment and furnace.

Figure S4 shows the kinematic base and the framework of the support frame. Part 2 is secured to Part 1 with bolts (Part 3). Cage assembly rods (Parts 4 and 5) are screwed into Part 2. Part 6, slid over the rods and held in place with set screws, is necessary to bring stability to Part 8. Figure S5 displays Parts 7-9 where Part 8c, with a hole pressed through the middle, is screwed into the threads of Part 6 which is critical in holding the fused silica tube (and therefore the heating elements) and the thermocouple secure. The thermocouple (Part 7) was threaded through Part 8f and held in place with a $0.4 \mathrm{~mm}$ Supeltex ferrule Part 8e. The fused silica tube (Part 9) is held in place using a Swagelok piece (Part 8a, 8d, 8f). 


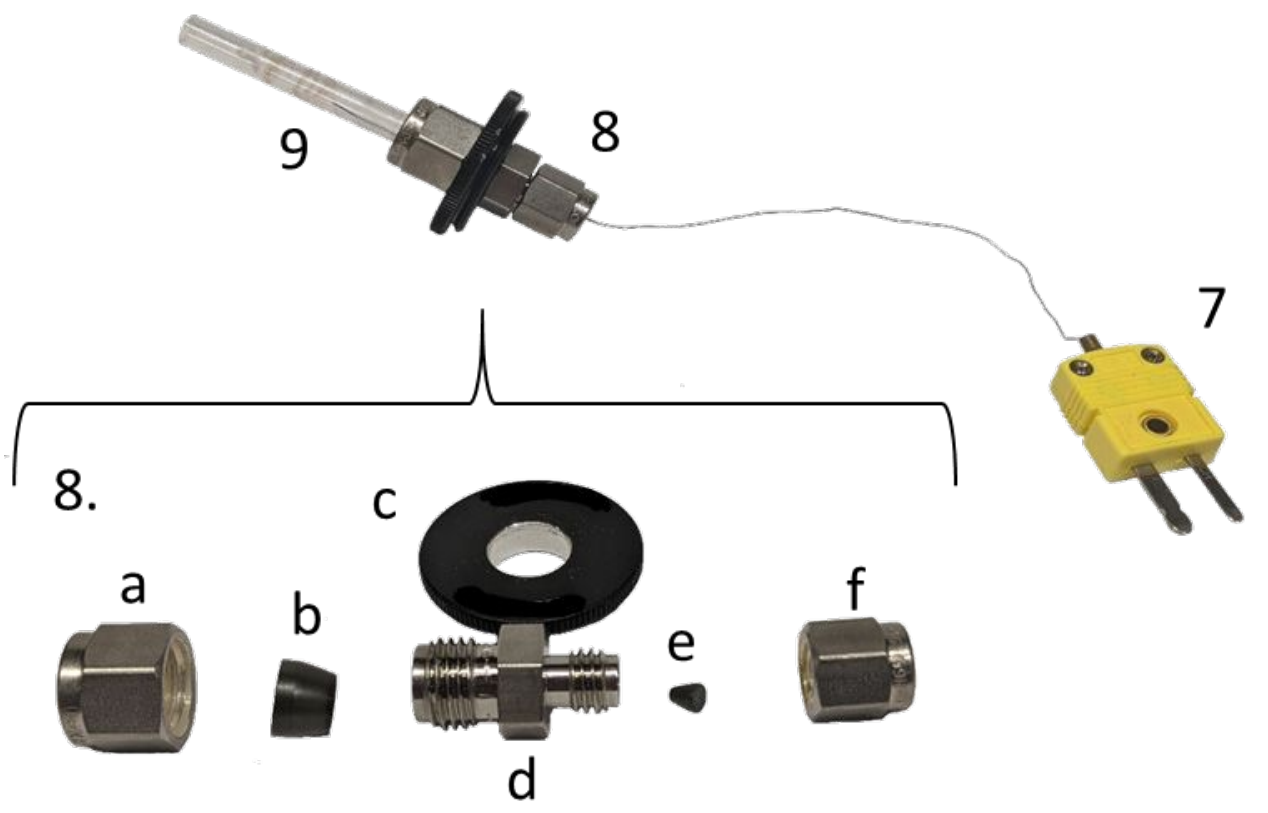

Figure S5. The sample environment designed to stabilize the Kanthal wires. The thermocouple (Part 7) provides temperature feedback and is held in place by piece 8 and is threaded to the center of the larger fused silica tube (Part 9).

Figure S6 displays each wire (formed by wrapped around a $6 \mathrm{~mm}$ bolt for shape, then set around a $6 \mathrm{~mm}$ od fused silica tube for stability) placed in double round hole mullite rods (Part 11) which are held in place using the set screws from Part 10. Each coil was then wrapped with flexible high temperature alumina silica insulation (Part 13). Wrapping the coils in insulation is a critical step in ensuring the furnace can reach temperatures above $1000{ }^{\circ} \mathrm{C}$.

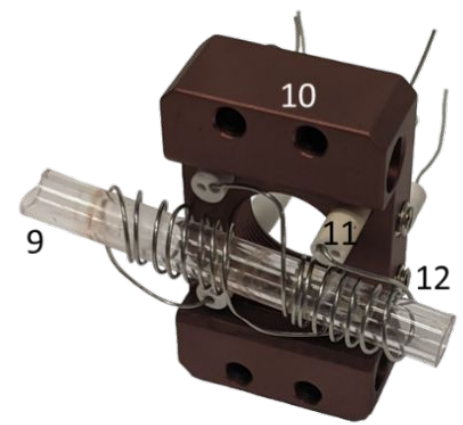

Figure S6. The Kanthal wires (Part 12) wrapped around a fused silica tube (Part 9) and held in place with mullite rods (Part 11) in the right-angle adapter (Part 10). 
Figure S7 shows the capillary containing the reactants secured to the motor (Part 17) (to decrease preferred orientation of crystallites) using an adaptor (Part 16) produced from a Swagelok straight fitting (1/16 in. Tube OD x 1/4 in. Male NPT, part number SS-100-1-4). The NPT end of the fitting was turned down to remove the threads and to reduce the outer diameter (OD) to approximately $8.5 \mathrm{~mm}$. The through hole for gas/water flow was then drilled to a depth of approximately $12.5 \mathrm{~mm}$ and bored to a slip fit for accommodating the $5 \mathrm{~mm}$ motor shaft. The adapter was attached to the motor shaft by two for $4-40$ set screws in holes drilled and tapped $90^{\circ}$ to each other at about half of the bore hole depth $(\sim 6 \mathrm{~mm})$.
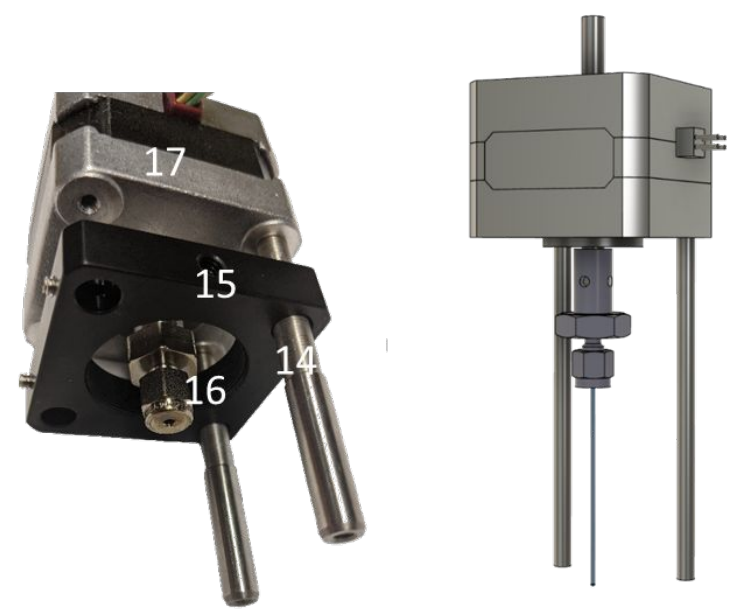

Figure S7. A real image (left) and schematic (right) of the motor and modified Swagelok adaptor.

1. Chupas, P. J.; Chapman, K. W.; Kurtz, C.; Hanson, J. C.; Lee, P. L.; Grey, C. P., A Versatile Sample-Environment Cell for Non-Ambient X-ray Scattering Experiments. J. Appl. Crystallogr. 2008, 41, 822-824. 